\title{
Cryopreservation of Ginseng Pollen
}

\author{
L.X. Zhang', W.C. Chang, Y.J. Wei, L. Liu, and Y.P. Wang \\ Institute of Special Crops and Wild Animals, Chinese Academy of Agricultural \\ Science, Zuojia, Jilin, China
}

Additional index words. cryogenic. distant hybridization, germplasm conservation, Panax ginseng, Panax quinquefolium

Abstract. Cryopreservation of pollen from two ginseng species -Panax ginseng L. and $P$. quinquefolium L.-was studied. Freezing anthers that served as pollen carriers to $-40 \mathrm{C}$ before liquid $\mathbf{N}$ storage affected pollen viability little after liquid $\mathbf{N}$ storage. Anther moisture content affected pollen viability significantly when stored in liquid $\mathbf{N}$. The ideal anther moisture content to carry pollen for liquid $N$ storage was $32 \%$ to $26 \%$ for $P$. ginseng and $27 \%$ to $17 \%$ for $P$. quinquefolium. Viability of pollen from $P$. quinquefolium anthers with $25.3 \%$ moisture content changed little after 11 months of liquid $\mathrm{N}$ storage.

Maintaining pollen viability and fertility for along period is important in plant breeding and conserving plant germplasm resources. Studies have shown that cryopreservation of pollen in liquid $\mathrm{N}(-196 \mathrm{C})$ is art ideal strategy for long-term preservation (Towill, 1985). We report a study of pollen viability and fertility in two ginseng species - Panax ginseng and $P$. quinquefolium -after liquid $\mathrm{N}$ storage. Fiveyear-old plants of both species were used. Anthers served as the pollen carriers because ginseng pollen is too small to handle individually. Unopened mature anthers were collected. Some of them were wrapped with paper, placed in 1.2-m-diameterplastic test tubes, and sealed with stoppers. The tubes with anthers were immersed in liquid $\mathrm{N}$, either directly or after prefreezing. Prefreezing was stepwise: temperature was lowered from 0 to $10 \mathrm{C}$ at $1 \mathrm{C} / \mathrm{min}$ and kept at $-10 \mathrm{C}$ for $15 \mathrm{~min}$, then cooled to $-40 \mathrm{C}$ at the same freezing rate, and kept at $-40 \mathrm{C}$ for $2 \mathrm{~h}$. Other anthers were placed in culture dishes and dried to various moisture contents with a forced-air fan. A sample of the fan-dried anthers was weighed and moisture content was determined. The rest of the anthers was stored in liquid $\mathrm{N}$.

Anther moisture content was determined from anther fresh weight and constant dry weight, which was obtained by drying anthers at $105 \mathrm{C}$ for $45 \mathrm{~min}$. After their removal from liquid $\mathrm{N}$, anthers were thawed in a 39 to $40 \mathrm{C}$ water bath (fast thawing). Pollen viability was estimated using the following three methods.

1) Staining. Anthers were cut open after being thawed and stained with $0 \%$ to $1 \%$ fuchsin basic for $10 \mathrm{~min}$ (Xue, 1985). They were rinsed with water three times and examined under a microscope. A pale-red color

Received for publication 30 Mar. 1992. Accepted for publication 12 Jan. 1993. Supported by National Natural Scientific Foundation of China. We thank Paul H. Li, Laboratory of Plant Hardiness, Dept. of Horticultural Sciences, Univ. of Minnesota, St. Paul, for his assistance. The cost of publishing this paper was defrayed in part by the payment of page charges. Under postal regulations, this paper therefore must be hereby marked advertisement solely to indicate this fact.

${ }^{1}$ Former Visiting Scholar at the Laboratory of Plant Hardiness, 1985-87. indicated that the pollen membrane was intact; this pollen was considered viable. A deep-red color indicated that the pollen membrane had been damaged; this pollen was considered nonviable (Xue, 1985).

2) Pollen germination. Pollen was germinated in culture dishes that contained $0.5 \%$ agar and (mg.liter $\left.{ }^{-1}\right) 250 \mathrm{CaCl}_{2}, 5$ boric acid, and 100 thiamine (Addicott, 1943; Brew baker and Kwack, 1963). Germination rates were determined after 2 days of culture at 24 to $26 \mathrm{C}$. About 180 to 200 pollen grains were counted from each storage treatment.

3) Pollen fertility. Pollen fertility was estimated by pollinating garden-grown ginseng plants. Flowers at full bloom and young flowers were removed from the inflorescence. About 15 to 20 flowers remained on an inflorescence. Flowers were emasculated and the inflorescence was covered with a paper bag. Pollination with cryopreserved pollen was carried out 2 days after emasculation. Three plants were used in each cross. Fertilization success was determined 1 month after pollination.

Effect of prefreezing. Panax ginseng anthers were removed from liquid $\mathrm{N}$ after 7 days of storage. Pollen viability was estimated by fuchsin basic staining and fertility. Prefreezing to $-40 \mathrm{C}$ before liquid $\mathrm{N}$ storage did not improve pollen viability significantly (Table 1 ). After 7 days of storage, a decrease of $\approx 50 \%$ in fertilization was observed compared to nonfrozen pollen. In contrast, prefreezing to -30 to $-50 \mathrm{C}$ is necessary for some hydrated plant tissues to ensure their viability after liquid $\mathrm{N}$ storage (Sakai and Sugawara, 1978). Because of the low moisture content in ginseng pollen, prefreezing is unnecessary.

Effect of anther moisture content. The

Table 1. Effect of prefreezing on Panax ginseng pollen viability after 7 days of liquid $\mathrm{N}$ storage.

\begin{tabular}{lcc}
\hline Treatment & $\begin{array}{c}\text { Pollen with } \\
\text { low-intensity } \\
\text { stain (\%) }\end{array}$ & $\begin{array}{c}\text { Fertilization } \\
\text { success } \\
(\%)\end{array}$ \\
\hline Control $^{2}$ & $93.5 \mathrm{a}^{y}$ & $53.3 \mathrm{a}$ \\
Without prefreezing & $75.4 \mathrm{a}$ & $20.0 \mathrm{a}$ \\
Prefreezing to -40C & $77.8 \mathrm{a}$ & $26.7 \mathrm{a}$ \\
\hline
\end{tabular}

${ }^{2}$ Pollen was not frozen.

${ }^{y}$ Mean separation within columns by LSD, $P \leq 0.05$. moisture content of $P$. ginseng and $P$. quinquefolium anthers significantly affected pollen viability after liquid $\mathrm{N}$ storage. Panax ginseng pollen from anthers with $49.2 \%$ or $35.3 \%$ moisture content had low germination and fertilization rates (Fig. 1). Anthers with $31.7 \%$ moisture content resulted in the highest germination and fertilization rates. Germination and fertilization rates decreased when anther moisture content dropped below $26.7 \%$. Panax quinquefolium pollen held in anthers with $36.2 \%$ or more moisture content had lower germination and fertilization rates after 7 days of liquid $\mathrm{N}$ storage. Germination decreased greatly when anther moisture content reached $13 \%$ (Fig. 2). Optimum moisture content of anthers to hold pollen for liquid $\mathrm{N}$ storage ranged from $32 \%$ to $26 \%$ for $P$. gin-

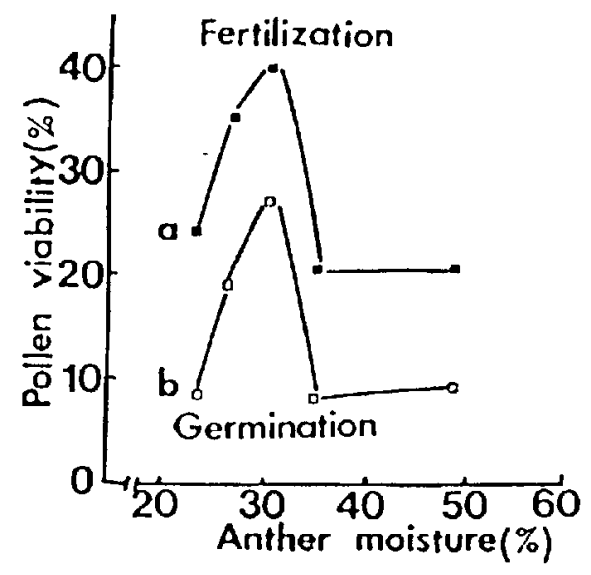

Fig. 1. Effect of anther moisture content on Panax ginseng pollen viability after 7 days of liquid $\mathrm{N}$ storage. Germination and fertilization percentages for fresh pollen were $24.6 \%$ and $33.3 \%$, respectively: (a) $\mathrm{y}=(-1215.15)+111.8637 \mathrm{x}-$ $3.2246 \mathrm{x}^{2}+0.0297 \mathrm{x}^{3}, r^{2}=0.9247$; (b) $\mathrm{y}=$ $(-1176.27)+106.3551 \mathrm{x}-3.0486 \mathrm{x}^{2}+0.0280 \mathrm{x}^{3}$, $r^{2}=0.8759$.

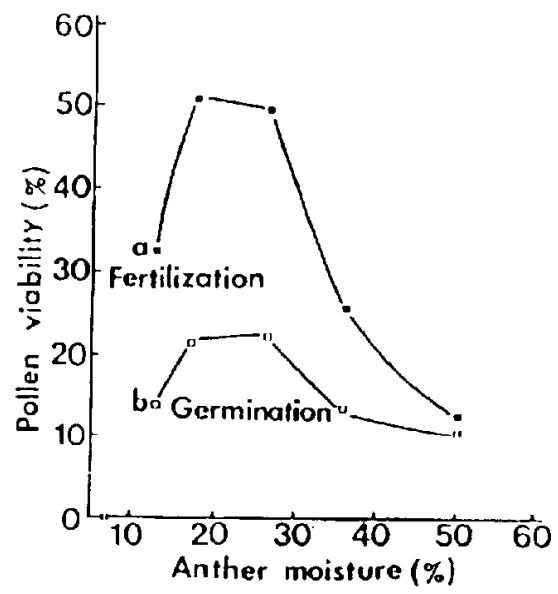

Fig. 2. Effect of anther moisture content on Panax quinquefolium pollen viability after 7 days of liquid $\mathrm{N}$ storage. Germination and fertilization percentages for fresh pollen were $17.0 \%$ and $49.1 \%$, respectively: (a) $\mathrm{y}=(-119.3386)+$ $18.8909 \mathrm{x}-0.6367 \mathrm{x}^{2}+6.2292 \times 10^{-3} \mathrm{x}^{3}, r^{2}=$ 0.9994 ; (b) $\mathrm{y}=(-47.3338)+7.6219 \mathrm{x}-0.2559 \mathrm{x}^{2}$ $+2.5328 \times 10^{-3} \mathrm{x}^{3}, r^{2}=0.9999$. 
seng and $27 \%$ to $17 \%$ for $P$. quinquefolium. Black walnut (Juglans nigra L. ) pollen had a higher in vitro germination rate after cryopreservation than fresh pollen (Farmer and Barnett, 1974). When rye (Secale cereale L. ) pollen with $11.5 \%$. moisture content was stored in liquid $\mathrm{N}$ for 14 days, fertilization rate was $15.1 \%$ higher than that of fresh pollen (Shi and Tian, 1989). Germination or fertilization success of ginseng pollen from anthers with suitable moisture content increased when pollen had been stored in liquid $\mathrm{N}$ compared with fresh pollen (Figs. 1 and 2). Viability of $P$. quinquefolium pollen from anthers with $25.3 \%$ moisture content after 11 months of liquid $\mathrm{N}$ storage, as estimated by staining, did not differ from that before storage (Table 2). Again, high anther moisture content adversely affected pollen viability (Table2) and fertilization (Fig. 3) after liquid N storage. Some interspecific

Table 2. Panax quinquefolium pollen viability after 11 months of liquid $\mathrm{N}$ storage.

\begin{tabular}{lcc}
\hline \hline $\begin{array}{l}\text { Anther } \\
\text { moisture }\end{array}$ & \multicolumn{2}{c}{ Pollen with low-intensity stain (\%) } \\
\cline { 2 - 3 } content $(\%)$ & Before storage & After storage \\
\hline 43.2 & $81.6 \mathrm{a}^{2}$ & $75.4 \mathrm{~b}$ \\
31.7 & $89.8 \mathrm{a}$ & $79.2 \mathrm{~b}$ \\
25.3 & $92.7 \mathrm{a}$ & $92.1 \mathrm{a}$ \\
\hline
\end{tabular}

${ }^{2}$ Mean separation within rows by $\mathrm{F}$ test, $P \leq 0.05$. hybrid seeds were obtained by fertilizing 5year-old $P$. ginseng plants at the late flowering stage with $P$. quinquefolium pollen after 11 months of liquid $\mathrm{N}$ storage. This is significant for interspecific hybridization among Panax

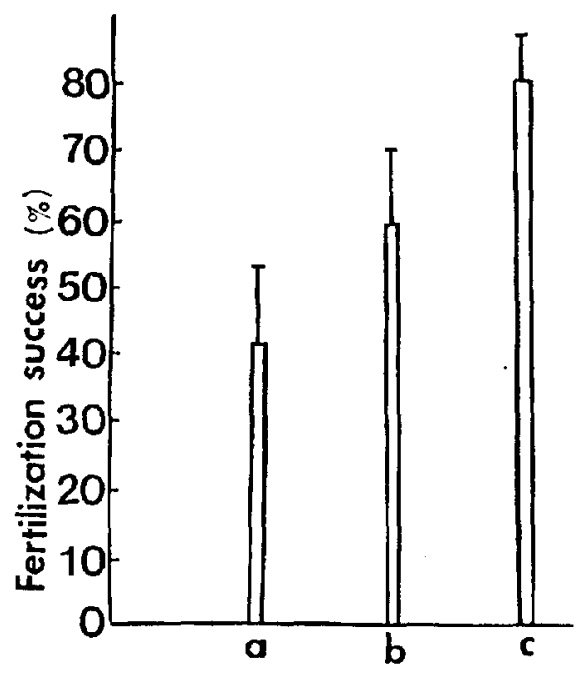

Fig. 3. Fertilization success of Panax quinquefolium pollen after 11 months of liquid $\mathrm{N}$ storage. (a) Pollen from anthers with $43.2 \%$ moisture content, (b) $31.7 \%$ moisture content, (c) $25.3 \%$ moisture content. species because they do not all flower at the same time. For example, inflorescences of $P$. quinquefolium usually appear 1 month later than those of $P$. ginseng in northeastern China, and fresh $P$. quinquefolium pollen has only about a 3- to 4-day life span.

\section{Literature Cited}

Addicott, F.T. 1943. Pollen germination and pollen tube growth as influenced by pure growth substances. Plant Physiol. 18:270-279.

Brewbaker, J.L. and B.H. Kwack. 1963. The essential role of calcium ion in pollen germination and pollen tube growth. Amer. J. Bot. 50:859-865.

Farmer, R.F. and P.E. Barnett. 1974. Low temperature storage of black walnut pollen. Cryobiology 11:366-369.

Sakai, A. and Y. Sugawara. 1978. Survival of plant germplasm in liquid nitrogen, p. 345-359. In: P.H. Li and A. Sakai (eds.). Plant cold hardiness and freezing stress. Academic, New York.

Shi, S.X. and T. Tian. 1989. Fertility and viability of rye pollen after storage in liquid nitrogen (-196C) for a year. Acta Phytophysiol. Sinica 15:393395 .

Towill, L.E. 1985. Low temperature and freeze/ vacuum-drying preservation of pollen, p. 172198. In: K.K. Kartha (ed.). Cryopreservation of plant cells and organs. CRC Press, Boca Raton, Fla.

Xue, Y.L. 1985. Experimental manual of plant physiology. Shanghai Science and Technology Publishing House, Shanghai. p. 328-329. 